IFN Working Paper No. 787, 2009

\title{
Supply Function Equilibria of Pay-as-Bid Auctions
}

Pär Holmberg 


\title{
Supply Function Equilibria of Pay-as-Bid Auctions ${ }^{1}$
}

\author{
Pär Holmberg ${ }^{2}$ \\ December 31, 2008
}

\begin{abstract}
This paper characterizes the Nash equilibrium in a pay-as-bid (discriminatory), divisible-good, procurement auction. Demand by the auctioneer is uncertain as in the supply function equilibrium model. A closed form expression is derived. Existence of an equilibrium is ensured if the hazard rate of the perfectly inelastic demand is monotonically decreasing and sellers have non-decreasing marginal costs. Multiple equilibria can be ruled out for markets, for which the auctioneer's demand exceeds suppliers' capacity with a positive probability. The derived equilibrium can be used to model strategic bidding behaviour in pay-as-bid electricity auctions, such as the balancing mechanism of United Kingdom. Offer curves and mark-ups of the derived equilibrium are compared to results for the SFE of a uniform-price auction.
\end{abstract}

Keywords: supply function equilibrium, pay-as-bid auction, discriminatory auction, divisible good auction, oligopoly, electricity market

JEL codes: C62, D43, D44, L11, L13, L94

\footnotetext{
${ }^{1}$ I am grateful to my supervisor Nils Gottfries for valuable comments, discussions and guidance. I appreciate comments by Ross Baldick, Börje Johansson, David Newbery, Andreas Westermark, Anders Ågren, and anonymous referees. I also want to thank seminar participants at Uppsala University in April 2005, participants at the supply function equilibrium workshop in Auckland, 2006, and seminar participants at the Research Institute of Industrial Economics (IFN) in October 2006. Nils-Henrik von der Fehr is acknowledged for awakening my interest in pay-as-bid auctions. The work has been financially supported by the Swedish Energy Agency, The Jan Wallander and Tom Hedelius Foundation, and the Research Program The Economics of Electricity Markets.

${ }^{2}$ Research Institute of Industrial Economics (IFN), Stockholm. Box 55665, SE-102 15 Stockholm, Sweden, phone +46 1847176 35, fax + 468665 4599. E-mail: Par.Holmberg@ifn.se.
} 


\section{INTRODUCTION}

The debate between proponents of settlements based on market-clearing prices and pay-as-bid schemes has a long history, most prominently in the context of auctions of treasury securities (Wilson, 2008). In recent years the U.S. Treasury and several other central banks converted to settlements based on market-clearing prices. This was partly motivated by that the revenue of the auctioneer was thought to be higher with a uniform-price auction (UPA) than with a payas-bid auction (PABA). If the auctioneer's revenue is higher in a uniform-price sales auction, then the auctioneer's procurement cost would be lower in a corresponding uniform-price procurement auction (Krishna, 2002). In spite of this, the conversion trend in electricity markets and treasury auctions tend to go in opposite directions, perhaps because bidders' valuations and their uncertainties in treasury auctions do not mirror suppliers' production costs and uncertainties in electricity markets. Most electricity auctions are organised as uniformprice auctions (UPAs), but one market - the balancing market in England \& Wales - has converted from UPA to PABA and similar conversions have been considered in other regions, e.g. California (Kahn et al., 2001). It was the belief of the British regulatory authority (Ofgem) that the reform, which also abolished capacity payments and replaced the day-ahead auction with bilateral contracting, would decrease mark-ups in wholesale electricity prices (Fabra et al., 2006). Prices have indeed fallen after the New Electricity Trading Arrangements (NETA) were introduced. But it is uncertain whether this was because of the changed market design or because of added capacity and forced and voluntary divestitures at the same time (Evans and Green, 2005). This paper contributes to the on-going discussion by characterizing strategic bidding behaviour in divisible-good, pay-as-bid procurement auctions and by comparing bidding in UPA and PABA. The model is primarily intended for electricity auctions. But a sales version of the model without capacity constraints would be useful when analyzing strategic bidding behaviour in pay-as-bid treasury auctions with non-competitive bids.

In this paper, the fundamental assumptions used in the supply function equilibrium (SFE) of UPAs are employed to derive a SFE of a PABA. As in Klemperer and Meyer's (1989) model it is assumed that production costs are common knowledge and that the auctioneer's demand is uncertain. In the Nash equilibrium of the static game, each supplier commits to the offer curve that maximizes its expected profit given competitors' offer curves. It was originally observed by Green and Newbery (1992) and Bolle (1992) that the set-up of the SFE model has many similarities with the organisation of electricity markets. Because in most electricity auctions, 
producers submit offer curves to a UPA and this is done before demand has been realised, i.e. demand is uncertain. Demand variation is added if offers are required to be valid for a whole day (long-lived bids), as was the case in the old electricity pool of England and Wales. Moreover, electricity production costs are fairly well-known. The validity of the SFE model has been questioned by von der Fehr and Harbord (1993), because smooth offer curves are assumed while they are stepped in most electricity markets, and at least theoretically this may drastically change the equilibrium bids. Still, three empirical studies of strategic bidding in the balancing market in Texas (ERCOT) suggest that the SFE model is approximately correct in describing the behaviour of the largest producers in this market (Hortacsu and Puller, 2008; Niu et al, 2005; Sioshansi and Oren, 2007).

First-order conditions for the PABA version of the SFE have previously been derived by Rudkevich (2003) and Wilson (2008), the latter model also considers transmission constraints. One contribution of this paper is that I derive a closed form expression of the equilibrium for a PABA with perfectly inelastic demand and symmetric producers with general cost functions. Perfectly inelastic demand is a good approximation for electricity markets, especially real-time markets, while the symmetry assumption simplifies the analysis. A corresponding closed form expression for UPAs has been derived by Anderson and Philpott (2002) and Rudkevich et al. (1998). Another contribution of the paper is that I analyze under what circumstances an equilibrium exists, which turns out to be far from self-evident in a PABA. A symmetric SFE of a PABA always exists if the hazard rate of demand is monotonically decreasing and marginal costs are non-decreasing. On the other hand, a symmetric SFE does not exist if there is any level of demand, for which all of the following three conditions are satisfied: Mark-ups are positive (i), the hazard rate is locally increasing (ii) and marginal costs are locally constant (iii).

As in a previous paper (Holmberg, 2008), it is considered that demand exceeds market capacity with a positive probability in electricity markets, i.e. the loss of load probability (LOLP) is positive. This is a realistic and very useful assumption, because multiple equilibria can be ruled out, also when the risk of power shortage is arbitrarily small. In practice, LOLP is estimated from the standard error in the demand forecast and from the probabilities of having production failures in individual plants Newbery (1998). Newbery shows that the LOLP estimated by the system operator in Britain decreases exponentially with the scheduled reserve margin. Using data provided in Newbery's paper and adjusting for that the system operator consistently overestimated LOLP, I roughly estimate LOLP during an half-hour to $0.1 \%$ when the scheduled reserve margin is $10 \%$ and that it roughly decreases by a factor 100 for every 
additional $10 \%$ of reserve capacity. ${ }^{3}$ However, this estimate is indeed very uncertain. It is only provided to give some feeling of the magnitude of LOLP and how it depends on the reserve capacity. It is no doubt that the LOLP is positive also for large levels of reserve capacity, and theoretically this is enough to provide uniqueness. An empirical question, however, is whether LOLP is too small for large reserve capacities, so that real producers do not consider it when submitting their offer curves.

The results of this paper, the equilibrium and the calculated difference between producers' expected profits in PABA and UPA, are used by Hästö and Holmberg (2006) to prove that average electricity prices in pay-as-bid procurement auctions are lower than average prices in uniform-price procurement auctions if demand is Pareto distributed of the second kind. Simulations in this paper suggest that the relative difference in mark-ups will be largest when the risk of power shortage is small. Earlier comparisons of SFE in UPA and PABA get the same ranking of the auctions, but for cases more restrictive in terms of industry costs and the number of firms. Federico and Rahman (2003) analyze a monopoly and perfectly competitive market with linear marginal costs considering a linear demand curve with uniformly distributed shocks. The treasury auction with non-competitive bids analyzed by Wang and Zender (2002) corresponds to an oligopoly market with constant marginal costs and no capacity constraints, in which the perfectly inelastic demand is given by an inverse Pareto distribution. In their case, demand has an increasing hazard rate and the SFE of the PABA can only exist for non-pivotal producers. Earlier studies by Fabra et al. (2006) and Son et al. (2004) also get the same ranking of average prices, using a multi-unit auction model of a duopoly market with constant marginal costs.

This paper is structured as follows. Notation and assumptions are presented in Section 2 and the unique SFE of a PABA is derived in Section 3. Section 4 compares SFE of UPA and PABA. Section 5 presents the conclusions.

\section{NOTATION AND ASSUMPTIONS}

Assume that there are $N \geq 2$ symmetric producers. Each producer $i$ submits an offer curve to the auction in order to maximize its expected profit $\mathrm{E}\left(\pi_{i}\right)$. The offer consists of a monotonically increasing supply function $S_{i}(p)$, where $p$ is the price. ${ }^{4}$ The inverse of the supply function is

\footnotetext{
${ }^{3}$ The values are estimated from Fig. 5 in Newbery (1998) and that capacity payments in the old pool were proportional to LOLP. It is assumed that the system operator have overestimated the LOLP by a factor 50 . This very uncertain factor is based on the reasoning in the appendix of Newbery (1998).

${ }^{4}$ Normally, electricity auctions do not accept decreasing supply functions.
} 
denoted by $p_{i}\left(S_{i}\right)$. $S_{-i}(p)$ and $S(p)$ denote the combined supply of firm $i$ 's competitors' and total supply in the marketplace, respectively. The marginal offer and system buy price - the average price the system operator pays the producers - both depend on total supply and they are denoted $p(S)$ and $\hat{p}(S)$, respectively. In a UPA, all accepted offers are paid the clearing price, i.e. $\widehat{p}_{U}(S) \equiv p_{U}(S)$, while $\hat{p}(S) \equiv \int_{0}^{S} p(x) d x / S$ in the PABA. As in Klemperer and Meyer's (1989) original work, only equilibria with twice continuously differentiable supply functions are considered. Thus in a symmetric equilibrium, $p_{i}\left(S_{i}\right)$ is smooth for $S_{i} \in\left(0, \varepsilon^{*} / N\right)$, where $\varepsilon^{*}$ is the total supply of all producers offered at the price cap $\bar{p}$. If firms are withholding capacity then $\varepsilon^{*}$ is less than $\bar{\varepsilon}$, the total capacity of all producers. All firms have identical cost functions $C\left(S_{i}\right)$, which are increasing, convex, and twice continuously differentiable up to the capacity constraint. Let the marginal cost function be continuous from the left at the capacity constraint and assume that it fulfils $C^{\prime}(\bar{\varepsilon} / N)<\bar{p}$. The marginal cost is infinite beyond the capacity constraint.

Denote perfectly inelastic demand by $\varepsilon$, its probability density function by $f(\varepsilon)$, its distribution function by $F(\varepsilon)$, and the inverse hazard rate, $\frac{1-F(\varepsilon)}{f(\varepsilon)}$, by $G(\varepsilon)$. The density function is continuously differentiable and has support on the interval $[0, \hat{\varepsilon}]$, where $\hat{\varepsilon}$ is maximum (unrationed) demand. It is assumed that $\hat{\varepsilon} \geq \bar{\varepsilon}$, i.e. the capacity constraints of all producers will bind with a positive probability, which is allowed to be arbitrarily small. Demand is zero above the reservation price (price cap). The system operator rations demand by forced disconnection of consumers.

\section{THE UNIQUE SYMMETRIC SFE OF A PAY-AS-BID AUCTION}

This section derives necessary and sufficient conditions for the SFE of a PABA. In Section 3.1, the first-order condition of a PABA is derived. It implies that each risk-neutral firm chooses a supply function that independently maximises expected profit for each of its units of production, given residual demand. This can be compared to the SFE of a uniform-price auction, in which a firm chooses a supply function that independently maximises profit for each demand outcome, given residual demand (Klemperer and Meyer, 1989). The first-order condition of the PABA is a differential equation which can be solved for general cost functions 
and the solution has one integration constant. In Section 3.2, the first-order condition is compared to Ramsey pricing and non-linear pricing. The integration constant is identified in Section 3.3 by considering that the risk of power shortage is positive; the symmetric equilibrium offers of all firms must reach the price cap exactly when the aggregate capacity constraint binds. This forms the end-condition.

The first-order condition and the end-condition must necessarily be satisfied in equilibrium. In Section 3.4, a sufficient second-order condition is derived. Unlike a UPA with perfectly inelastic demand, it is not possible to prove that all increasing, smooth, symmetric supply functions satisfying the necessary conditions are supply function equilibria of a PABA. In particular, it turns out that if the hazard rate of demand is locally increasing and marginal costs are sufficiently flat, then symmetric pure strategy equilibria of a PABA do not exist. On the other hand, I show that a pure strategy equilibrium always exists if the hazard rate is monotonically decreasing and marginal costs are non-decreasing.

In section 3.5 it is shown that the first-order condition becomes particularly simple if demand has a Pareto distribution of the second kind, for which the inverse of the hazard rate is linear.

\subsection{The first-order condition}

It is assumed that firm $i$ 's competitors follow a symmetric equilibrium candidate. The firstorder condition derived below must necessarily be fulfilled if the strategy implied by the symmetric equilibrium candidate locally maximises firm $i$ 's expected profit. To avoid differentiability problems, all considered deviations of firm $i$ satisfy $p_{i}(0)=p_{j}(0)$ and $p_{i}\left(\varepsilon^{*} / N\right)=p_{j}\left(\varepsilon^{*} / N\right) \forall j$. Hence, for the considered deviations we always have that $S_{-i}(p(0))=0$ and that $\varepsilon^{*}-S_{-i}\left(p\left(\varepsilon^{*}\right)\right)=\varepsilon^{*} / N$. These restrictions on the deviations are alright as long as we are calculating a necessary condition of a profit maximum. Sufficiency for a global maximum is checked later on, in Section 3.4. For demand outcome $\varepsilon \leq \varepsilon^{*}$, the accepted output from firm $i$ is given by $\varepsilon-S_{-i}(p(\varepsilon))$. Note that firm $i$ influences $p(\varepsilon)$ by means of its chosen offer function $p_{i}\left(S_{i}\right)$. The profit from an accepted offer of an infinitesimally small unit of supply is $\left(p\left(S_{i}\right)-C^{\prime}\left(S_{i}\right)\right) d S_{i}$. The firm's profit for some shock outcome $\varepsilon$ can be calculated by summing the profit from each unit. With infinitesimally small production units, the sum becomes an integral. 


$$
\pi_{i}(\varepsilon)=\int_{0}^{\varepsilon-S_{-i}(p(\varepsilon))}\left[p_{i}\left(S_{i}\right)-C^{\prime}\left(S_{i}\right)\right] d S_{i} \quad \text { if } \varepsilon \leq \varepsilon^{*} .
$$

The expected profit of firm $i$ is calculated by integrating across all shock outcomes and by weighting each outcome by its probability density $f(\varepsilon)$.

$$
E\left(\pi_{i}\right)=\int_{0}^{\varepsilon^{*}} f(\varepsilon) \int_{0}^{\varepsilon-S_{-i}(p(\varepsilon))}\left[p_{i}\left(S_{i}\right)-C^{\prime}\left(S_{i}\right)\right] d S_{i} d \varepsilon+\int_{\varepsilon^{*}}^{\hat{\varepsilon}} f(\varepsilon) \int_{0}^{\varepsilon^{*} / N}\left[p_{i}\left(S_{i}\right)-C^{\prime}\left(S_{i}\right)\right] d S_{i} d \varepsilon .
$$

The second term of this expression represents the contribution from demand outcomes exceeding market supply, in which case the accepted supply from firm $i$ is $\varepsilon^{*} / N$. The domain of the integration is plotted in Fig. 1.

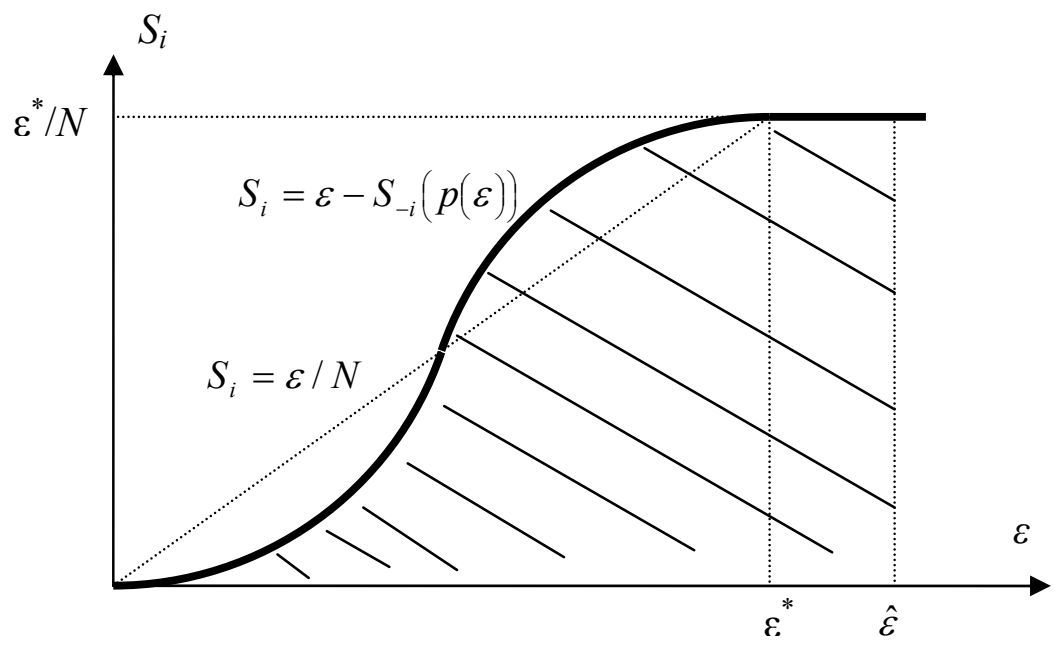

Figure. 1. The domain of the integration in the calculation of the expected profit.

Now the order of integration is reversed. The new integration limits follow from the domain of the integration shown in Fig. 1.

$$
\begin{aligned}
& \mathrm{E}\left\{\pi_{i}\left[p_{i}\left(S_{i}\right)\right]\right\}=\int_{0}^{\varepsilon^{*} / N}\left[p_{i}\left(S_{i}\right)-C^{\prime}\left(S_{i}\right)\right] \int_{S_{i}+S_{-i}\left[p_{i}\left(S_{i}\right)\right]}^{\varepsilon^{*}} f(\varepsilon) d \varepsilon d S_{i}+ \\
& +\int_{0}^{\varepsilon^{*} / N}\left[p_{i}\left(S_{i}\right)-C^{\prime}\left(S_{i}\right)\right] \int_{\varepsilon^{*}}^{\hat{\varepsilon}} f(\varepsilon) d \varepsilon d S_{i}=\int_{0}^{\varepsilon^{*} / N}\left[p_{i}\left(S_{i}\right)-C^{\prime}\left(S_{i}\right)\right] \int_{S_{i}+S_{-i}\left[p_{i}\left(S_{i}\right)\right]}^{\hat{\varepsilon}} f(\varepsilon) d \varepsilon d S_{i}= \\
& =\int_{0}^{\varepsilon^{*} / N} \underbrace{\left[p_{i}\left(S_{i}\right)-C^{\prime}\left(S_{i}\right)\right]\left[1-F\left(S_{i}+S_{-i}\left[p_{i}\left(S_{i}\right)\right]\right)\right]}_{\varphi_{i}\left[S_{i}, p_{i}\left(S_{i}\right)\right]} d S_{i} .
\end{aligned}
$$

This result can be interpreted as follows. A firm's expected profit is given by a sum over the expected profit from each of its units of supply. In its turn, the expected profit of a unit is given by its mark-up $\left[p_{i}\left(S_{i}\right)-C^{\prime}\left(S_{i}\right)\right]$ times the probability that the unit's offer is accepted, i.e. the 
probability that demand exceeds $S_{i}+S_{-i}\left[p_{i}\left(S_{i}\right)\right]$. Proceeding with the analysis, we note that firm $i$ chooses the offer function $p_{i}\left(S_{i}\right)$ such that its expected profit $\mathrm{E}\left[\pi_{i}\right]$ is maximised. That is, the firm faces a calculus of variation problem with the fixed terminal points $p_{i}(0)=p_{j}(0)$ and $p_{i}\left(\varepsilon^{*} / N\right)=p_{j}\left(\varepsilon^{*} / N\right)$. As there are no occurrences of $p_{i}^{\prime}\left(S_{i}\right)$ in the integrand, the Euler equation degenerates to the following equation (Chiang, 1992):

$$
\begin{aligned}
& \frac{\partial \varphi_{i}}{\partial p_{i}}=1-F\left[S_{-i}\left(p_{i}\left(S_{i}\right)\right)+S_{i}\right]-S_{-i}{ }^{\prime}\left(p_{i}\left(S_{i}\right)\right)\left(p_{i}\left(S_{i}\right)-C^{\prime}\left(S_{i}\right)\right) f\left[S_{-i}\left(p_{i}\left(S_{i}\right)\right)+S_{i}\right]=0, \\
& \forall S_{i} \in\left(0, \varepsilon^{*} / N\right) .
\end{aligned}
$$

The functional $\varphi_{i}\left[S_{i}, p_{i}\left(S_{i}\right)\right]$ represents the contribution to expected profit from an infinitesimally small unit of supply. Thus, the Euler equation implies that, given residual demand, expected profit from each unit is maximised independently of the firm's other units. Because only equilibria with smooth and increasing supply functions are considered, (2) can be written as follows:

$$
\begin{aligned}
& 1-F\left[S_{-i}(p)+S_{i}(p)\right]-S_{-i}^{\prime}(p)\left(p-C^{\prime}\left(S_{i}(p)\right)\right) f\left[S_{-i}(p)+S_{i}(p)\right]=0, \\
& \forall p: S_{i}(p) \in\left(0, \varepsilon^{*} / N\right) .
\end{aligned}
$$

In this paper only symmetric SFE are considered, i.e. $S_{-i}(p) \equiv(N-1) S_{i}(p)$. Thus (3) can be further simplified to:

$$
1-F\left[N S_{i}(p)\right]-(N-1) S_{i}^{\prime}(p)\left(p-C^{\prime}\left(S_{i}(p)\right)\right) f\left[N S_{i}(p)\right]=0, \forall p: S_{i}(p) \in\left(0, \varepsilon^{*} / N\right)
$$

A positive risk of power shortage implies that $1-F(\varepsilon)>0 \quad \forall \varepsilon \in[0, \bar{\varepsilon}]$. Thus $p>C^{\prime}$ and

$S_{i}^{\prime}(p)>0$. Introducing the inverse hazard rate function, $G(\varepsilon)$, (4) can be written as:

$$
G\left[N S_{i}(p)\right]-(N-1) S_{i}^{\prime}(p)\left(p-C^{\prime}\left(S_{i}(p)\right)\right)=0, \forall p: S_{i}(p) \in\left(0, \varepsilon^{*} / N\right) .
$$

This can be compared with the first-order condition of a UPA for symmetric producers and perfectly inelastic demand (Holmberg, 2008).

$$
S_{i}(p)-(N-1) S_{i}^{\prime}(p)\left(p-C^{\prime}\left(S_{i}(p)\right)\right) \equiv 0 .
$$

Note that the two first-order conditions are identical if $G(N x)=x$.

In Appendix it is shown that the solution to the first-order condition in (4) is:

$$
p(\varepsilon)=\frac{A-\int^{\varepsilon}(N-1) C^{\prime}(u / N) f(u)[1-F(u)]^{\frac{N-1}{N}-1} d u}{N[1-F(\varepsilon)]^{\frac{N-1}{N}}} \quad \forall \varepsilon \in\left[0, \varepsilon^{*}\right],
$$


where $A$ is an integration constant.

\subsection{The first-order condition as Ramsey prices and non-linear pricing}

In this section, I will show that the first-order condition is consistent with the inverse elasticity rule, i.e. Ramsey pricing (Tirole 2003), and that it has similarities with non-linear pricing. For a unit $S_{i}$, (3) can be written in the following form:

$$
\frac{p-C^{\prime}\left(S_{i}(p)\right)}{p}=\frac{1-F\left[S_{i}+S_{-i}(p)\right]}{S_{-i}^{\prime}(p) p f\left[S_{i}+S_{-i}(p)\right]}=-\frac{\left\{1-F\left[S_{i}+S_{-i}(p)\right]\right\} / p}{\frac{\partial\left\{1-F\left[S_{i}+S_{-i}(p)\right]\right\}}{\partial p}} .
$$

The probability that unit $S_{i}$ 's offer is accepted, $1-F\left[S_{i}+S_{-i}(p)\right]$, can be interpreted as the residual demand of this unit (Bulow and Klemperer, 1996). Thus (8) is the inverse elasticity rule applied to a unit $S_{i}$ facing a residual demand of $1-F\left[S_{i}+S_{-i}(p)\right]$.

The first-order condition in (8) also has similarities with optimal nonlinear pricing for the continuum-of-types case (Tirole, 2003; Wilson, 1997). Let types be distributed according to the density $f(\theta)$. Then it can be shown that a monopolist's optimal unit price for a unit $q$ is given by: 5

$$
\frac{p-c}{p}=\frac{1-F\left[\theta_{q}^{*}(p)\right]}{\theta_{q}^{*^{\prime}}(p) p f\left[\theta_{q}^{*}(p)\right]},
$$

where $\theta_{q}^{*}(p)$ denotes the type of consumer that is indifferent between buying and not buying the $q$ 'th unit at price $p$. An important difference between nonlinear pricing and SFE of a PABA is that $\theta_{q}^{*}(p)$ is exogenous, while $S_{-i}(p)$ is endogenous. Another key difference is that the price per unit increases with supply in a SFE, whereas the price per unit decreases with supply in the non-linear pricing literature. If $\theta_{q}^{* \prime}(p) \leq 0$, then it follows from (9) that the hazard rate must be increasing if the non-linear price is to decrease, and this is a standard assumption in the non-linear pricing literature (Tirole, 2003; Wilson, 1997). We will see later that increasing hazard rates are problematic for SFE, and this can be attributed to the fact that supply functions are required to be upward sloping.

\footnotetext{
${ }^{5}$ Note that the relation can be further simplified to $\frac{p-c}{p}=\frac{1-F\left[\theta_{q}^{*}(p)\right]}{\theta_{q}^{*}(p) f\left[\theta_{q}^{*}(p)\right]}$, because $\theta_{q}^{*^{\prime}}(p)=\frac{\theta_{q}^{*}(p)}{p}$ (Tirole,
} 2003). The simplified expression is the one normally found in the non-linear pricing literature. 


\subsection{Determining the integration constant}

Analogous to the derivation of the SFE of a UPA, the integration constant $A$ in (7) allows for a continuum of potential equilibria (Klemperer and Meyer, 1989). In this section, I argue that the integration constant can be uniquely determined if, as in (Holmberg, 2008), the capacity constraint binds with a positive probability.

If $\varepsilon^{*}<\bar{\varepsilon}$, some capacity is withheld from the auction. However, it cannot be optimal to withhold power. Any offer is accepted with a positive probability and a producer will find it profitable to offer previously withheld units at or just below the price cap. Offering its whole capacity will increase the contribution to expected profit of demand outcomes $\varepsilon>\varepsilon^{*}$, while the possible profit reduction associated with demand outcomes $\varepsilon \leq \varepsilon^{*}$ can be made arbitrarily small.

The highest offer in the auction must equal the price cap, because demand is perfectly inelastic. Otherwise, the highest offer could be increased without lowering the probability that its associated unit is accepted. Moreover, as stated in Section 2, the analysis is confined to equilibria with twice continuously differentiable supply functions. Hence $S_{i}^{\prime}(p)<\infty$, implying that $p^{\prime}(\varepsilon)>0 .{ }^{6}$ Thus by construction supply functions cannot have horizontal segments at the price cap.

In summary, the price of the marginal unit must reach the price cap but not before the capacity constraint binds. Hence, the integration constant can be pinned down by the endcondition $p(\bar{\varepsilon})=\bar{p}$. It follows from (7) that

$$
p(\varepsilon)=\frac{N[1-F(\bar{\varepsilon})]^{N-1} \frac{\bar{c}}{p}+\int_{\varepsilon}^{\bar{\varepsilon}}(N-1) C^{\prime}(u / N) f(u)[1-F(u)]^{\frac{N-1}{N}-1} d u}{N[1-F(\varepsilon)]^{\frac{N-1}{N}}} \forall \varepsilon \in[0, \bar{\varepsilon}] .
$$

The same end-condition has been used to derive a unique SFE for UPAs (Baldick and Hogan, 2001; Holmberg, 2008). In the multi-unit auction by von der Fehr and Harbord (1993), the market-clearing price also reaches the price cap for high demand outcomes in UPAs. Offering supply all the way up to the price cap also has empirical support. In U.S. markets it has been

\footnotetext{
${ }^{6}$ The assumption simplifies the proof but is not critical. Allowing for offers with perfectly elastic segments does not change the result because, as in a Bertrand game, it is profitable to deviate from a symmetric equilibrium candidate with horizontal segments by slightly lowering ones horizontal offer to undercut competitors' horizontal segments (Holmberg, 2008), as long as the horizontal segment is above marginal cost. The deviation significantly increases the probability that an offer is accepted, while the price reduction can be made arbitrarily small.
} 
observed that producers offer their last units of power at an extremely high price, a phenomenon called hockey-stick bidding (Hurlbot et al., 2004). There are often offers at the price cap (£9999/MWh) in the reformed market of Britain, and in some delivery periods such offers have even been accepted (Roques et al, 2005).

\subsection{The second-order condition}

Consider a symmetric equilibrium candidate satisfying the first-order condition in (4). For this candidate, let $\breve{p}(\varepsilon)$ be the marginal offer as a function of demand. The symmetric supply functions associated with the candidate are designated by $\breve{S}_{i}(p)$. If the aggregate supply of competitors equals $\breve{S}_{-i}$, then - as shown by (2) - the expected profit from any unit of firm $i$ is at a local extremum if the firm submits $\breve{S}_{i}(p)$. In equilibrium, it is necessary, but not sufficient, that the local extremum is a local maximum for each unit. Otherwise a producer could find a profitable unilateral deviation from $\breve{S}_{i}(p)$. Conditions under which the expected profit is at a local maximum for each unit is stated in claim i) of Theorem 1 below. Note that it also applies to markets without capacity constraints. Claim ii) is a sufficient condition, which ensures that the local extremum is a global maximum for each production unit. In this case, the expected profit of the firm is also globally maximized and $\breve{S}_{i}(p)$ is a symmetric NE.

\section{Theorem 1}

Consider an equilibrium candidate satisfying the first-order condition in (4).

i) $\left[\breve{p}(\varepsilon)-C^{\prime}(\varepsilon / N)\right] G^{\prime}(\varepsilon)+G(\varepsilon) C^{\prime \prime}(\varepsilon / N) \geq 0 \forall \varepsilon \in(0, \bar{\varepsilon})$ is a necessary condition for it to be a SFE.

ii) If $G^{\prime}(\varepsilon)>0 \forall \varepsilon \in[0, \bar{\varepsilon}]$, then the solution to equation (10) is a SFE (sufficient condition).

Proof: See Appendix.

The derivative of the hazard rate is equal to $\frac{-G^{\prime}(x)}{G^{2}(x)}$. Hence, an increasing inverse hazard rate is equivalent to a decreasing hazard rate. It now follows from claim i) of Theorem 1 that if the hazard function is locally upward sloping, then smooth symmetric equilibria with positive mark-ups can be ruled out if marginal costs are sufficiently flat. That SFE with positive mark- 
ups do not exist in PABA with constant marginal costs and increasing hazard rates generalizes a result by Wang \& Zender (2002). Their treasury auction model corresponds to a pay-as-bid procurement auction, in which producers have constant marginal costs and no capacity constraints. If demand is given by the inverse Pareto distribution, which has an upward sloping hazard rate, they prove that the only possible SFE is that firms' offer curves are equal to their marginal costs, i.e. mark-ups must be zero. In a market with capacity constraints that bind with a positive probability, mark-ups are positive for some demand outcomes and also the Bertrand solution can be ruled out if the hazard rate is locally increasing. There is some intuition behind the non-existent equilibrium. In the PABA, an increasing hazard rate, i.e. decreasing inverse hazard rate, implies that increasing solutions $\breve{S}_{i}(p)$ must be very concave, $\breve{S}_{i}^{\prime \prime}(p)<<0$, if the symmetric first-order condition in (5) is to be satisfied, especially if marginal costs are constant. This means that the residual demand of each firm becomes very convex. Existence is problematic under those circumstances, see for example non-existence results for monopolists or Cournot players facing sufficiently convex (residual) demand (Gravelle and Rees, 1996).

\subsection{The Pareto distribution of the second kind}

As shown below, the Pareto distribution of the second kind has the useful property that its inverse hazard rate is linear, which implies that the first-order condition becomes particularly simple. The probability distribution is

$$
F(x)=1-\beta^{\frac{1}{\alpha}}(\alpha x+\beta)^{\frac{-1}{\alpha}}
$$

and the probability density

$$
f(x)=\beta^{\frac{1}{\alpha}}(\alpha x+\beta)^{\frac{-1}{\alpha}-1} .
$$

Hence, the inverse of its hazard rate is

$$
G(x)=\frac{1-F(x)}{f(x)}=\alpha x+\beta .
$$

The parameter $\beta$ determines $f(0)$ as illustrated in Figure 2. When $\alpha$ is large, $f$ has a steep negative slope for small arguments and a thick tail for large arguments, vice versa for small $\alpha$. The density function is decreasing and strictly convex for all $\alpha, \beta>0$. Thus the Pareto distribution of the second kind may be a reasonable approximation of the auctioneer's demand in balancing markets, in which small imbalances are more likely than large imbalances. 


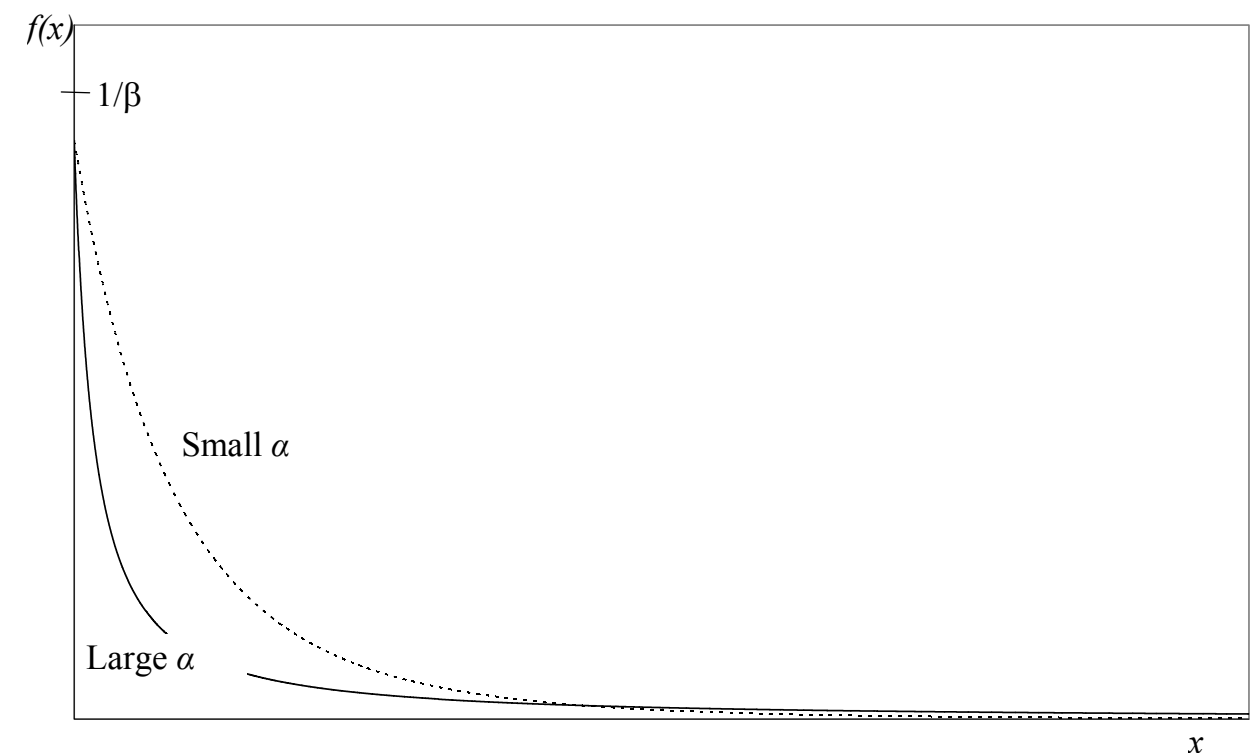

Figure 2. The effect of $\alpha$ and $\beta$ on the probability density function $f(x)$.

It follows from (13) that the inverse hazard rate of the Pareto distribution is non-decreasing for $\alpha \geq 0$, which according to Theorem 1 implies that pure-strategy SFE of PABA exists as long as marginal costs are non-decreasing.

With the Pareto distribution of the second kind, the first-order condition of the PABA in (4) can be simplified to

$$
\alpha N S_{i}(p)+\beta-(N-1) S_{i}^{\prime}(p)\left(p-C^{\prime}\left(S_{i}(p)\right)\right) \equiv 0,
$$

which resembles the first-order condition of the UPA in (6). It follows from (10) that the equilibrium marginal offer in a PABA with a Pareto distribution of the second kind is

$$
p(\varepsilon)=\frac{N(\alpha \bar{\varepsilon}+\beta)^{\frac{1-N}{\alpha \nu}} \bar{p}+\int_{\varepsilon}^{\bar{\varepsilon}}(N-1) C^{\prime}(u / N)(\alpha u+\beta)^{\frac{1-N}{\alpha N}-1} d u}{N(\alpha \varepsilon+\beta)^{\frac{1-N}{\alpha N}}} .
$$

\section{Comparing pay-as-bid and uniform-price auctions}

\subsection{Comparison of bid curves}

In this section equilibrium offers in pay-as-bid and uniform-price auctions are compared for a simple example. Demand is assumed to be perfectly inelastic and marginal costs are assumed to be constant and equal to $c$.

Using (14), it is straightforward to calculate the equilibrium marginal offer in PABA. 


$$
p_{p}(\varepsilon)=\frac{(\bar{p}-c)(\alpha \varepsilon+\beta)^{\frac{N-1}{\alpha N}}}{(\alpha \bar{\varepsilon}+\beta)^{\frac{N-1}{\alpha N}}}+c
$$

or equivalently

$$
p_{p}(\varepsilon)=\frac{(\bar{p}-c)\left(\frac{\mu \varepsilon}{\bar{\varepsilon}}+1\right)^{\frac{N-1}{\alpha N}}}{(\mu+1)^{\frac{N-1}{\alpha N}}}+c
$$

where $\mu=\frac{\alpha \bar{\varepsilon}}{\beta}$. From this equation it can be shown that

$$
\hat{p}_{p}(\varepsilon)=\frac{\int_{0}^{\varepsilon} p_{p}(t) d t}{\varepsilon}=(\bar{p}-c) \frac{\left(\frac{\mu \varepsilon}{\bar{\varepsilon}}+1\right)^{\frac{N-1}{\alpha N}+1}-1}{\frac{\mu \varepsilon}{\bar{\varepsilon}}\left(\frac{N-1}{\alpha N}+1\right)(\mu+1)^{\frac{N-1}{\alpha N}}}+c .
$$

This is the system buy price in PABA, i.e. the average price paid to the producers at the demand level $\varepsilon$.

The equilibrium marginal offer for symmetric firms in a UPA can be calculated from (Holmberg, 2008),

$$
p_{U}(\varepsilon)=\frac{\bar{p} \varepsilon^{N-1}}{\bar{\varepsilon}}+(N-1) \varepsilon^{N-1} \int_{\varepsilon}^{\bar{\varepsilon}} \frac{C^{\prime}(u / N) d u}{u^{N}} \quad \forall[0, \bar{\varepsilon}] .
$$

In the special case of constant marginal costs, this can be simplified to:

$$
p_{U}(\varepsilon)=(\bar{p}-c)\left(\frac{\varepsilon}{\bar{\varepsilon}}\right)^{N-1}+c .
$$

The offer curves implied by (15), (16) and (18) are compared in Fig. 3 and Fig. 4. In a UPA, the marginal offer (and system buy price) equals the marginal cost at zero supply (Klemperer and Meyer, 1989). The unit with the lowest marginal cost still contributes to profits, as it is paid the marginal offer for $\varepsilon>0$. It is also true in general that the lowest offer in the pay-as-bid auction is higher than the marginal cost, at least if $G(0)>0$. This is realised from the first-order condition in (5). Accordingly, the system buy price is generally higher in PABA when demand is sufficiently small. In both procurement auctions, all units except for the most expensive one are offered below the price cap. Thus the system buy price in a PABA is always below the price cap. In the uniform-price auction, on the other hand, the system buy price equals the price cap when demand equals or exceeds market capacity. Hence, the system buy price is generally lower in the PABA when demand is sufficiently high. That the minimum system buy price is higher and the maximum system buy price is lower in PABA compared to UPA is in 
agreement with the experimental finding that price volatility is lower in PABAs than in UPAs (Rassenti et al., 2003).

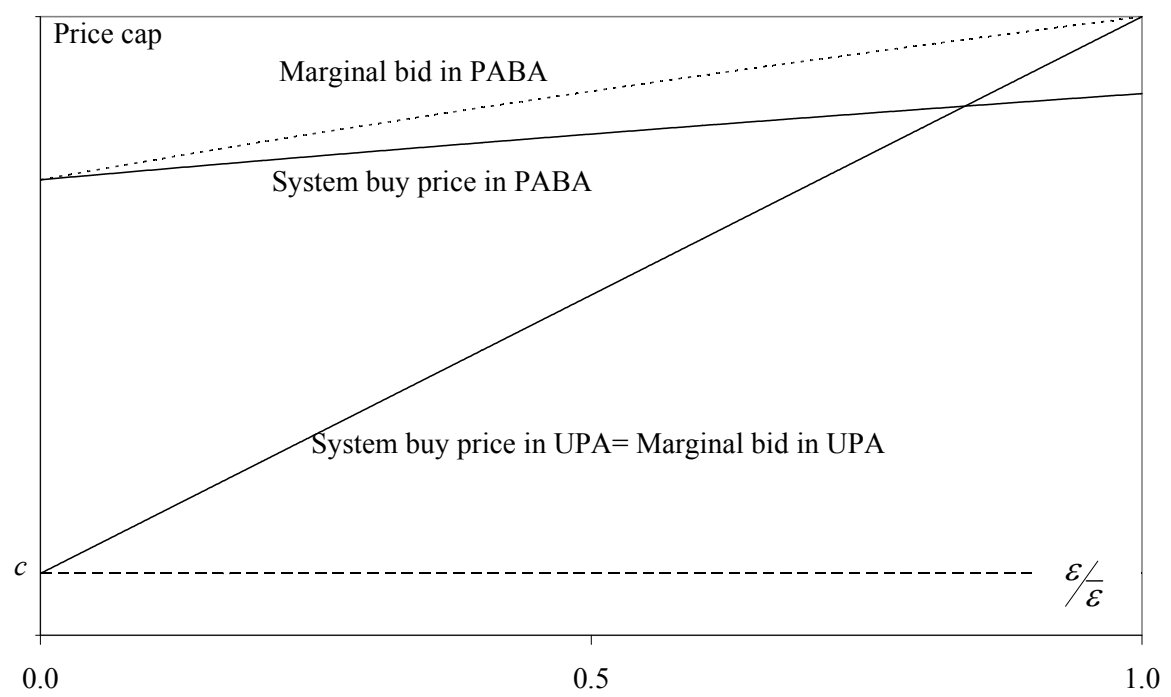

Figure 3. Prices as a function of demand are compared for the uniform-price auction (UPA) and pay-as-bid auction (PABA). $N=2, \mu=1$ and $\alpha=1$.

In Fig. 3 the marginal offer in PABA is higher than or equal to the marginal offer in UPA. As stated below this is generally true for non-decreasing marginal costs if $G(N x) \geq x$.

Theorem 2. For the same level of demand, the marginal offer in PABA is higher than or equal to the marginal offer in UPA if $G(\varepsilon) \geq \varepsilon / N$ for $\varepsilon \in[0, \bar{\varepsilon}]$.

Proof: See Appendix.

The mark-up at zero supply in PABA is determined by $G(0)=\beta$. Increasing $\mu$ reduces $\beta$, and the mark-up decreases; compare Fig. 3 and 4 . The intuition here is that reducing $\beta$ increases the probability of having low demand outcomes (see Fig. 2) and accordingly producers put more weight on low demand outcomes when calculating their optimal pay-as-bid offers. 


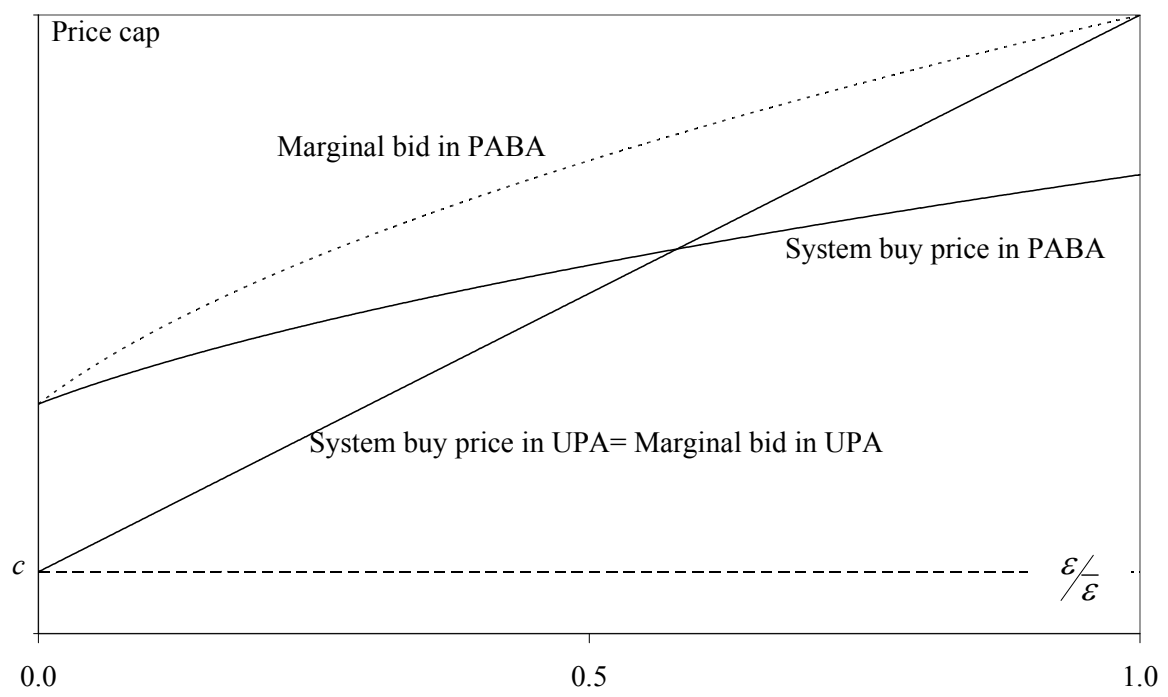

Figure 4. Prices as a function of demand are compared for the uniform-price auction (UPA) and pay-as-bid auction (PABA). N=2, $\mu=10$ and $\alpha=1$.

When the power imbalance is negative, i.e. power production exceeds demand, the system operator needs to sell back power to producers in the balancing market, which becomes a sales auction (Holmberg, 2008). Firms' alternative to not buying back power is to pay the marginal cost to meet their contracted production. Thus to make money on their balancing-down bids, firms offer to buy back power below their marginal cost. As the imbalance is perfectly inelastic, a price floor, $\underline{p}$, is needed to prevent the price from becoming arbitrarily small. Let the negative constant $\underline{\varepsilon}$ represent the total down-regulation capacity in the market. The supply function equilibrium of the sales auction is anti-symmetric to a corresponding procurement auction. Imagine a procurement auction for which $c^{*}=-c, \bar{p}^{*}=-\underline{p}$ and $\bar{\varepsilon}^{*}=-\underline{\varepsilon}$. Moreover, assume that the probability density of system demand in the fictional procurement auction is equal to the probability density of the system sales. Then the equilibrium of the sales auction is anti-symmetric to the equilibrium of the fictional procurement auction, i.e. $S_{j}(p)=-S_{j}{ }^{*}(-p)$. An equilibrium with both positive and negative imbalances is shown in Fig. 5. Note that the marginal offer/bid and system buy/sell price in PABA is discontinuous at zero demand, while they are continuous in a UPA. 


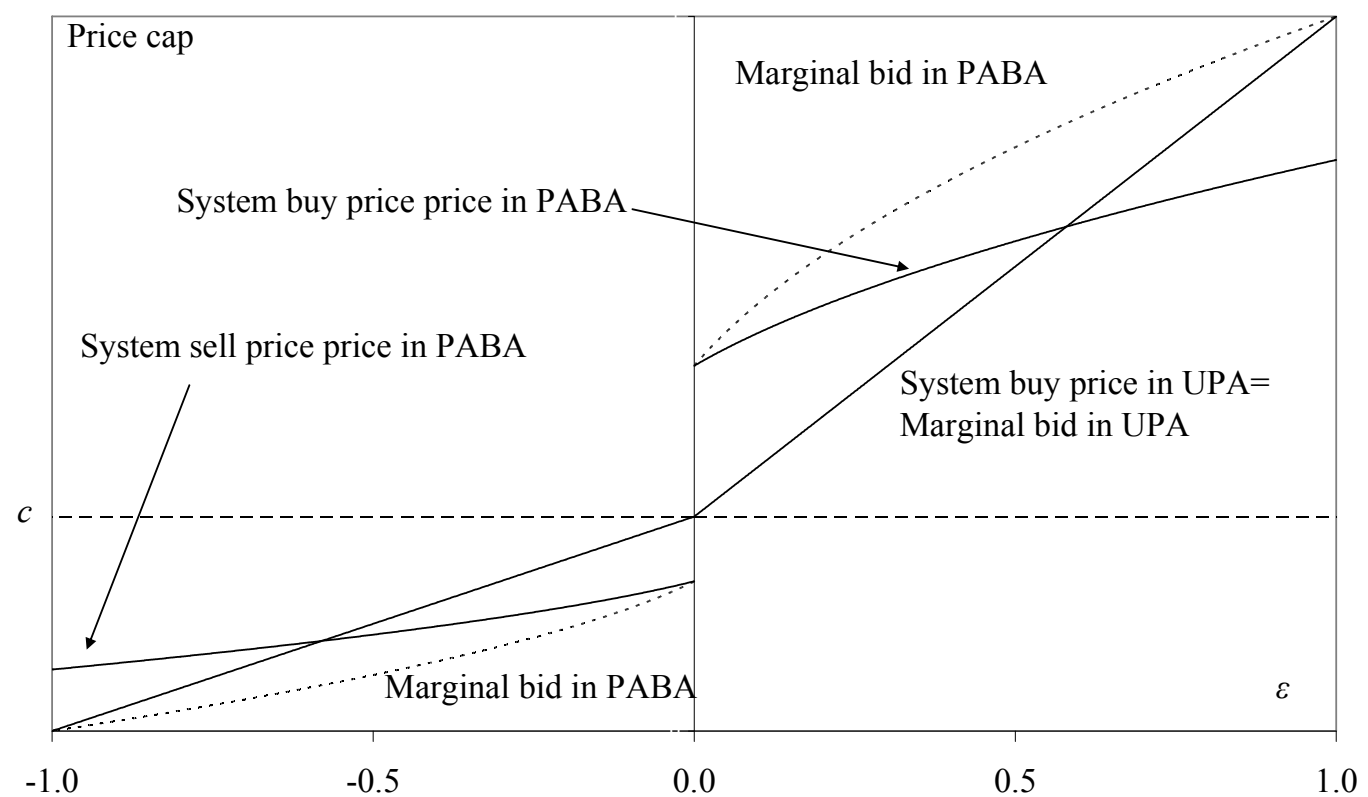

Figure 5. Prices as a function of the imbalance are compared for the uniform-price auction (UPA) and pay-as-bid auction (PABA). N=2, $\mu=10, \alpha=1, \bar{\varepsilon}=1, \underline{\varepsilon}=-1, \underline{p}=0$, and $c=0.3 \bar{p}$.

\subsection{Comparing expected revenues of producers}

In this paper, demand is assumed to be perfectly inelastic. As a result, total production in a pay-as-bid and uniform-price auction are identical. Furthermore, only symmetric equilibria are considered. This means that for every demand outcome, the most cost-effective generators will be accepted in both procurement auctions. Hence, production costs are the same in both auctions for all outcomes. System buy prices and mark-ups will differ, however. Producers' mark-ups in the two auction formats are ordered by comparing their expected revenues. It follows from (1) that the total expected revenue for all firms in a PABA is

$$
R_{p}=\int_{0}^{\bar{\varepsilon}}(1-F(S)) p(S) d S=\int_{0}^{\bar{\varepsilon}}(1-F(\varepsilon)) p(\varepsilon) d \varepsilon .
$$

For constant marginal costs and the Pareto distribution of the second kind, (11) and (14) can be used to derive the following expression (Holmberg, 2005).

$$
R_{P}=(\bar{p}-c) \bar{\varepsilon} g_{P}\left(\alpha, N, \frac{\alpha \bar{\varepsilon}}{\beta}\right)+\beta^{\frac{1}{\alpha}} c \int_{0}^{\bar{\varepsilon}}(\alpha \varepsilon+\beta)^{\frac{-1}{\alpha}} d \varepsilon
$$

where 


$$
g_{P}\left(\alpha, N, \frac{\alpha \bar{\varepsilon}}{\beta}\right)=\frac{\left(1+\frac{\alpha \bar{\varepsilon}}{\beta}\right)^{\frac{-1}{\alpha N}+1}-1}{\left(1-\frac{1}{\alpha N}\right) \frac{\alpha \bar{\varepsilon}}{\beta}\left(\frac{\alpha \bar{\varepsilon}}{\beta}+1\right)^{\frac{N-1}{\alpha N}}}
$$

It can be shown that $\beta^{\frac{1}{\alpha}} c \int_{0}^{\bar{\varepsilon}}(\alpha \varepsilon+\beta)^{\frac{-1}{\alpha}} d \varepsilon$ in (20) is the expected production cost (Holmberg, 2005). Thus $(\bar{p}-c) \bar{\varepsilon} g_{P}\left(\alpha, N, \frac{\alpha \bar{\varepsilon}}{\beta}\right)$ is a measure of the mark-up.

The total expected revenue for firms in a UPA is ${ }^{7}$

$$
R_{U}=\int_{0}^{\bar{\varepsilon}} f(\varepsilon) \varepsilon p_{U}(\varepsilon) d \varepsilon+(1-F(\bar{\varepsilon})) \bar{\varepsilon} \bar{p}
$$

The second term is the contribution from demand outcomes exceeding market capacity. The following can be shown for constant marginal costs and the Pareto distribution of the second kind (Holmberg, 2005):

$$
R_{U}=(\bar{p}-c) \bar{\varepsilon} g_{U}\left(\alpha, N, \frac{\alpha \bar{\varepsilon}}{\beta}\right)+\beta^{\frac{1}{\alpha}} c \int_{0}^{\bar{\varepsilon}}(\alpha \varepsilon+\beta)^{\frac{-1}{\alpha}} d \varepsilon
$$

where

$$
g_{U}\left(\alpha, N, \frac{\alpha \bar{\varepsilon}}{\beta}\right)=\frac{N}{\left(\frac{\alpha \bar{\varepsilon}}{\beta}\right)^{N}} \int_{0}^{\frac{\alpha \bar{\varepsilon}}{\beta}}(1+t)^{\frac{-1}{\alpha}} t^{N-1} \mathrm{~d} t .
$$

Subtracting (20) from (23) yields:

$$
R_{U}-R_{P}=(\bar{p}-c) \bar{\varepsilon}\left[g_{U}\left(\alpha, N, \frac{\alpha \bar{\varepsilon}}{\beta}\right)-g_{P}\left(\alpha, N, \frac{\alpha \bar{\varepsilon}}{\beta}\right)\right]
$$

The contour plot of $\frac{g_{U}\left(\alpha, N, \frac{\alpha \bar{\varepsilon}}{\beta}\right)-g_{P}\left(\alpha, N, \frac{\alpha \bar{\varepsilon}}{\beta}\right)}{g_{U}\left(\alpha, N, \frac{\alpha \bar{\varepsilon}}{\beta}\right)}$ in Figure 6 illustrates the relative decrease of mark-ups when switching from a UPA to a PABA. The plot is not very sensitive to the number of firms. As the ratio is positive over a wide range of parameters, it seems that

${ }^{7}$ Analogously $R_{p}=\int_{0}^{\bar{\varepsilon}} f(\varepsilon) \hat{\varepsilon} \hat{p}(\varepsilon) d \varepsilon+(1-F(\bar{\varepsilon})) \bar{\varepsilon} \hat{p}(\bar{\varepsilon})$. By means of integration by parts and the definition of $\hat{p}(\varepsilon)$ it is straightforward to verify that this expression is equal to (19). 
$R_{U}-R_{P} \geq 0$. Indeed, using (21), (24) and (25) this inequality is proven in a companion paper (Hästö and Holmberg, 2006).

Figure 6 shows that switching from a UPA to a PABA almost eliminates mark-ups, i.e.

$\underline{g_{U}-g_{P}} \approx 1$, in the area for which both $\bar{\varepsilon}>>\beta$ and $\alpha<1$, which corresponds to that in which $g_{U}$

$G(\varepsilon)$ is small. As can be seen in Figure 7, this area also corresponds to a very low risk of power shortage. In the extreme case when $\alpha \rightarrow 0$ and $\beta \rightarrow 0$, demand is zero with certainty. On the other hand, mark-ups are roughly the same, i.e. $\frac{g_{U}-g_{P}}{g_{U}} \approx 0$, for either large $\alpha$ (fat tail of the probability density function) or small $\bar{\varepsilon}$ (small capacity), both of which imply a high risk of power shortage.

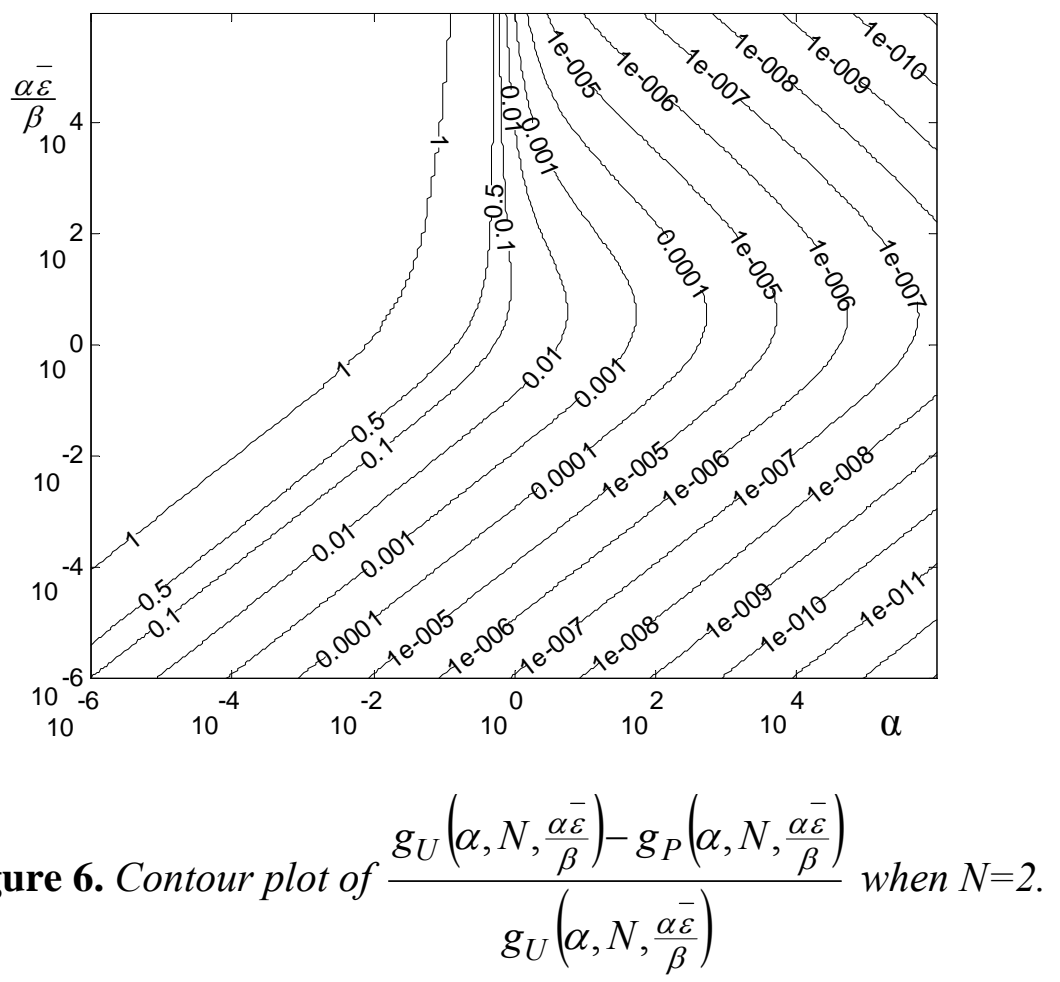




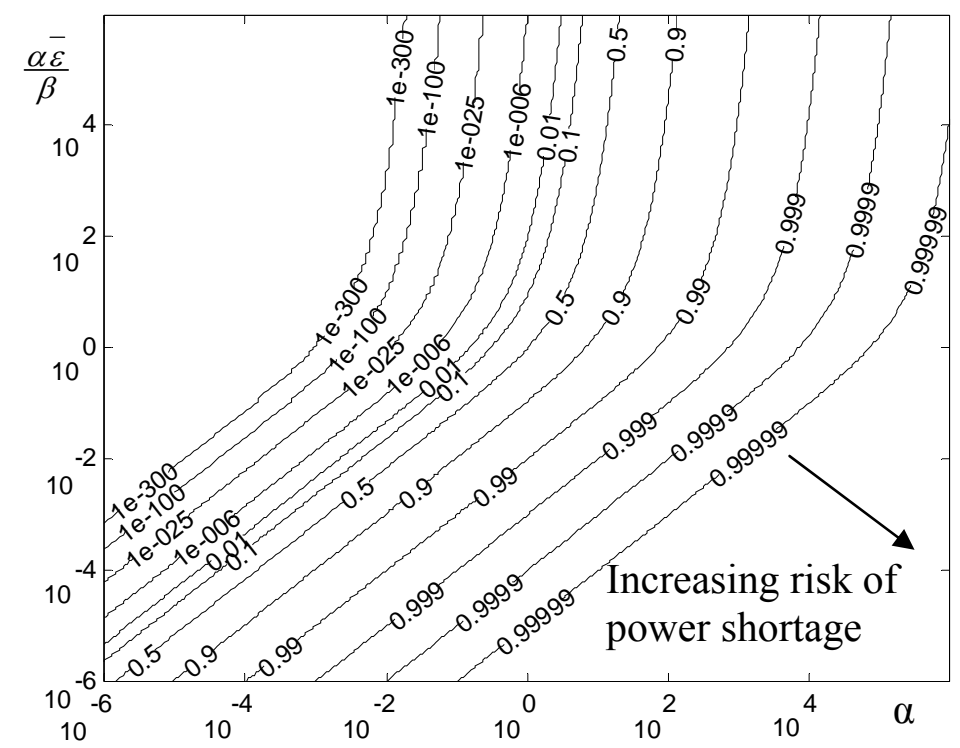

Figure 7. Contour plot of $1-F(\bar{\varepsilon})=\left(\frac{\alpha \bar{\varepsilon}}{\beta}+1\right)^{\frac{-1}{\alpha}}$, the probability of a power shortage.

Hästö and Holmberg (2006) prove that firms' expected revenues are weakly larger in UPA than in PABA also for increasing marginal costs if the perfectly inelastic demand is Pareto distributed of the second kind. Firms' total expected revenues are the same in both auctions under perfect competition and monopoly (Holmberg, 2005). The perfectly inelastic demand is independent of the auction design. Thus larger producer-revenues in UPA imply that the demand-weighted average price is weakly lower in PABAs than in UPAs. Furthermore, as production costs are the same in both procurement auctions, average mark-ups are weakly lower in PABAs than in UPAs. Lower average prices in PABA imply a reduced procurement cost of the auctioneer compared to UPA. In a corresponding sales auction, the revenue of the auctioneer is higher in PABA (Krishna, 2002). Thus the auctioneer (and electricity consumers) will prefer the PABA auction both when it is buying and selling power if both positive and negative imbalances are given by the Pareto distribution of the second kind.

\section{CONCLUSIONS}

The supply function equilibrium (SFE) framework for uniform-price auctions (UPAs) is similar to the organisation of most electricity markets and is often employed to model strategic bidding in such markets. This paper derives a SFE for a pay-as-bid auction (PABA), such as 
the balancing market of Britain. Some of the results are also relevant for pay-as-bid treasury auctions with random non-competitive bids.

In contrast to SFE of UPA, SF equilibria of PABA depend on the probability distribution of demand, and so does the existence of pure strategy equilibria. It is shown that a SFE of a PABA always exists if the hazard rate of the perfectly inelastic demand is monotonically decreasing and marginal costs are non-decreasing. On the other hand, a SFE does not exist if there is any level of demand, for which all of the following three conditions are satisfied: Mark-ups are positive (i), the hazard rate is locally increasing (ii) and marginal costs are locally constant (iii). These circumstances are rather restrictive, especially as most standard probability distributions, such as the normal and uniform distribution, have increasing hazard rates. In particular, there is a considerable risk that these non-existence conditions are satisfied in balancing markets, because system imbalances are approximately normally distributed (Garcia and Kirschen, 2006), and marginal electricity production costs are roughly stepped, i.e. approximately locally constant. That SFE with positive mark-ups do not exist in PABA with constant marginal costs and increasing hazard rates generalizes a result by Wang \& Zender (2002). Applying their results for pay-as-bid treasury auctions to a corresponding procurement auction, they would imply that firms without capacity constraints would offer their supply at the constant marginal cost if demand follows an inverted Pareto distribution, which has an increasing hazard rate. With capacity constraints that bind with a positive probability also the Bertrand solution can be excluded and no SFE would exist in PABA. The paper by Fabra et al. (2006) also indicates that there is a larger risk to lack a pure strategy equilibrium in the PABA.

Generally, the system buy price is higher in PABAs compared to UPAs when the realized demand outcome is sufficiently low, but lower when realized demand is sufficiently high. This seems to be in agreement with the experimental finding that price volatility is lower in PABAs than in UPAs (Rassenti et al., 2003). The UK experience, however, is that price volatility increased after the introduction of NETA, at least initially. One explanation is that bids were long lived in the pool and that they are short lived in the new balancing mechanism. Moreover, the original NETA design was flawed, because penalty charges encouraged producers to retain their own balancing capacity to avoid imbalances in their own production instead of offering the balancing capacity to the market (Roques et al., 2005). This reduced the liquidity and increased the volatility in the balancing market. The volatility reduced considerably after this problem was fixed.

A companion paper (Hästö and Holmberg, 2006) uses the results derived in this paper to prove that electricity consumers prefer PABA to UPA if demand is perfectly inelastic and 
given by Pareto distribution of the second kind. ${ }^{8}$ Simulations in this paper suggest that the relative mark-up difference in the two auction formats is largest when the risk of power shortage is very small, but then mark-ups should be so small, due to excess capacity, that they do not matter anyway. The relative difference is small when the loss of load probability (LOLP) is very high, i.e. when mark-ups would really hurt. It has been proven that mark-ups in the two auction formats are identical under monopoly pricing and perfect competition. In summary, the results suggest that switching to PABA will be most beneficial when the risk of power shortage is neither extremely small nor extremely large and when competition is imperfect without being extremely bad. The ranking result agrees with previous theoretical studies (Fabra et al. 2006; Federico and Rahman, 2003; Son et al., 2004; Wang and Zender, 2002) but contradicts the findings of an experimental study (Rassenti et al., 2003) and an agent based simulation (Bower and Bunn, 2001). The experimental set-up differs to most of the theoretical set-ups in that demand was certain in the experiment (even if the players had to figure it out by themselves), and this may explain the different ranking results. Certain demand implies infinitely many equilibria, so the experimental results, unlike the theoretical results, were driven by equilibrium selection. Market prices were not publicly available in the agent based simulation, so agents with a large market share gained a significant informational advantage in a discriminatory auction, thereby facing less competitive pressure (Bower and Bunn, 2001). But market prices are publicly available in electricity markets, so Bower and Bunn's result may not be so relevant for such markets. An empirical study by Evans and Green (2005) show that the change in the NETA design had little impact on average prices. One could take this as evidence that average prices are similar in UPA and PABA, which does not necessarily contradict the theoretical findings. But one has to be somewhat careful, because NETA did not only change the auction format but also changed other aspects of the market design - capacity payments were abolished, for example.

A general assumption of the theoretical analyses is that firms are risk-neutral. Introducing risk aversion does not change the SFE of a UPA, as firms receive the best price for every demand outcome, given the bids of competitors. A risk-averse firm in a PABA, however, would put less weight on high-demand outcomes when profits are high and more weight on low-demand outcomes when profits are low. Hence, given the bids of competitors, risk-averse

\footnotetext{
${ }^{8}$ In the balancing market, the auctioneer (and electricity consumers) will prefer PABA to UPA if both positive and negative imbalances are given by the Pareto distribution of the second kind. For positive imbalances, when the system operator is buying additional power from producers, the average price is lower in PABA compared to the UPA For negative imbalances, when the system operator is selling back power to producers, the average price is higher in the PABA compared to the UPA.
} 
firms decrease their bids to increase profits for low-demand outcomes. Intuitively this would also be true in equilibrium. It appears that with risk-averse bidders, the advantages (from the auctioneer's viewpoint) of PABAs are likely to increase. Another advantage of PABAs is that the risk for tacit collusion is lowered compared to UPAs. This is shown by both Fabra (2003) and Klemperer (2002).

But PABA also has disadvantages compared to UPA. Federico and Rahman (2003) find that under perfect competition and elastic demand, output and welfare is lower in PABA compared to UPA, even if consumer surplus is larger in PABA. As noted earlier PABA has a higher risk of lacking a pure strategy equilibrium. It could be a disadvantage for both consumers and producers, as prices might vary unpredictably, either because of chaotic bidding or mixed strategy bidding as in Genc (2008). Kahn et al. (2001) also point out that in a UPA it is optimal for small firms to simply bid their marginal costs while in a PABA, all firms must forecast market prices if they are to receive any contributions to profits. This introduces an additional fixed cost for small firms, which could be disadvantageous to competition in the long-run.

\section{ACKNOWLEDGMENTS}

I am grateful to my supervisor Nils Gottfries for valuable comments, discussions and guidance. I appreciate comments by Ross Baldick, Börje Johansson, David Newbery, Andreas Westermark, Anders Ågren, and anonymous referees. I also want to thank seminar participants at Uppsala University in April 2005 and participants at the supply function equilibrium workshop in Auckland, 2006. Nils-Henrik von der Fehr is acknowledged for awakening my interest in pay-as-bid auctions. The work has been financially supported by the Swedish Energy Agency and Jan Wallander's foundation.

\section{REFERENCES}

E. J. Anderson and A. B. Philpott (2002), "Using supply functions for offering generation into an electricity market", Operations Research, vol. 50, No. 3, pp. 477-489.

R. Baldick and W. Hogan (2001), Capacity constrained supply function equilibrium models for electricity markets: Stability, non-decreasing constraints, and function space iterations, POWER Paper PWP-089, University of California Energy Institute. 
F. Bolle (1992), "Supply function equilibria and the danger of tacit collusion. The case of spot markets for electricity", Energy Economics, vol. 14, pp. 94-102.

J Bower and D. Bunn (2001), "Experimental analysis of the efficiency of uniform-price versus discriminatory auctions in the England and Wales electricity market", Journal of Economic Dynamics \& Control, vol. 25, pp. 561-592.

J. Bulow and P. Klemperer (1996), “Auctions versus negotiations”, The American Economic Review, vol. 86, No. 1, pp. 180-194.

A. Chiang (1992), Dynamic Optimization, New York: McGraw Hill, Inc.

J. Evans and R. Green (2005), Why did British electricity prices fall after 1998?, Working Paper, Birmingham University, UK.

N. Fabra (2003), "Tacit collusion in repeated auctions: uniform versus discriminatory", Journal of Industrial Economics, vol. 51, No. 3, pp. 271-293.

N. Fabra, N-H von der Fehr, and D. Harbord (2006), "Designing Electricity Auctions", Rand Journal of Economics, vol. 37, No. 1, pp. 23-46.

N.H. von der Fehr \& D. Harbord (1993), "Spot Market Competition in the UK Electricity Industry", The Economic Journal, vol. 103, pp. 531-546.

G. Federico and D. Rahman (2003), "Bidding in an electricity pay-as-bid auction", Journal of Regulatory Economics, vol. 24, No. 2, pp. 175-211.

M. P. Garcia and D. S. Kirschen (2006), "Forecasting System Imbalance Volumes in Competitive Electricity Markets“, IEEE Transactions on Power Systems, vol. 21, no. 1, pp. 240-248.

T. Genc (2008), Discriminatory Versus Uniform-Price Electricity Auctions with Supply Function Equilibrium, Working Paper, Department of Economics, University of Guelph, Canada. 
H. Gravelle and R. Rees (1996), Microeconomics, New York: Addison Wesley Longman Ltd.

R.J. Green and D.M. Newbery (1992), "Competition in the British Electricity Spot Market", Journal of Political Economy, vol. 100, No. 5, pp. 929-953.

P. Hästö and P. Holmberg (2006), "Some inequalities related to electricity auctions”, Applied Mathematics Letters, vol. 19, No. 8, pp. 814-819.

P. Holmberg (2005), Comparing supply function equilibria of Pay-as-Bid and Uniform-price auctions, Working Paper 2005:17, Department of Economics, Uppsala University.

P. Holmberg (2008), “Unique Supply Function Equilibrium with Capacity Constraints”, Energy Economics, vol. 30, pp. 148-172.

A. Hortacsu and S. Puller (2008), "Understanding Strategic Bidding in Multi-Unit Auctions: A Case Study of the Texas Electricity Spot Market", Rand Journal of Economics, vol. 39, No. 1, pp. 86-114.

D. Hurlbut, K. Rogas, and S. Oren (2004). "Hockey Stick Pricing: How the Public Utility Commission of Texas is Dealing with Potential Price Gouging”. The Electricity Journal, vol. 17, pp. 26-33.

N.L. Johnson, S. Kotz, and N. Balakrishnan (1994), Continuous Univariate Distributions, New York: John Wiley \& Sons.

A.E. Kahn, P.C. Cramton, R.H. Porter, and R.D. Tabors (2001), "Uniform Pricing or Pay-asBid pricing: A dilemma for California and beyond", The Electricity Journal, vol. 14, No. 6, pp. 70-79.

P.D. Klemperer and M.A. Meyer (1989), "Supply function equilibria in an oligopoly under uncertainty", Econometrica, vol. 57, pp. 1243-1277. 
P.D. Klemperer (2002), "What really matters in auction design”, Journal of Economic Perspectives”, vol. 16, pp. 169-190.

V. Krishna (2002), Auction theory, Academic Press: San Diego.

D. M. Newbery (1998), "Pool Reform and Competition in Electricity", Ch..5, pp.117-166 in M. Beesley (ed.) Regulating Utilities: Understanding the Issues, London: Institute of Economic Affairs.

H. Niu, R. Baldick, and G. Zhu (2005), "Supply Function Equilibrium Bidding Strategies With Fixed Forward Contracts", IEEE Transactions on power systems, vol. 20, No. 4, pp. 1859-1867.

L. Råde and B. Westergren (1990), Beta, Mathematics Handbook, Lund: Studentlitteratur, 1990.

S. Rassenti, V. Smith and B. Wilson (2003), "Discriminatory price auctions in electricity markets: low volatility at the expense of high price levels", Journal of Regulatory Economics, vol. 23, pp. 109-123.

F. A. Roques, D. M. Newbery and W. J. Nuttall (2005), "Investment Incentives and Electricity Market Design: the British Experience", Review of Network Economics, vol.4, No. 2.

A. Rudkevich, M. Duckworth and R. Rosen (1998), "Modeling electricity pricing in a deregulated generation industry: The potential for oligopoly pricing in a poolco", The Energy Journal, vol. 19, No. 3, pp. 19-48.

A. Rudkevich (2003), “Supply function equilibrium: theory and applications”, Proceedings of the 36th Annual Hawaii International Conference on System Sciences, 6-9 Jan 2003.

R. Sioshansi and S. Oren (2007), "How Good are Supply Function Equilibrium Models: An Empirical Analysis of the ERCOT Balancing Market", Journal of Regulatory Economics, vol. 31, No. 1, pp. 1-35. 
Y. S. Son, R. Baldick, K.H. Lee, and S. Siddiqi (2004), "Short-Term Electricity Market Auction Game Analysis: Uniform and Pay-as-Bid Pricing”, IEEE Transactions on Power Systems, vol. 19, No. 4, pp. 1990-1998.

J. Tirole (2003), The Theory of Industrial Organization, Cambridge: MIT Press.

J. Wang and J. Zender (2002), “Auctioning divisible goods”, Economic Theory, Vol. 19, pp. 673-705, 2002.

R. Wilson (1997), Nonlinear Pricing, New York: Oxford University Press.

R. Wilson (2008), "Supply function equilibrium in a constrained transmission system", Operations Research, Vol. 56, pp. 369-382.

\section{APPENDIX}

\section{Solving the first-order condition}

In order to solve the differential equation in (4), it is transformed into an equation in terms of $p(\varepsilon)$, the price of the marginal unit as a function of the demand, instead of $S_{i}(p)$. The same transformation is applied when solving the differential equation associated with the SFE of a UPA (Anderson and Philpott, 2002; Holmberg, 2008; Rudkevich et al., 1998). In the symmetric equilibrium, $\varepsilon=N S_{i}(p(\varepsilon))$ and $S_{i}^{\prime}=\frac{1}{N p^{\prime}(\varepsilon)}$, if $\varepsilon<\varepsilon^{*}$. Thus

$$
1-F(\varepsilon)-\frac{(N-1)}{N p^{\prime}(\varepsilon)}\left[p(\varepsilon)-C^{\prime}(\varepsilon / N)\right] f(\varepsilon)=0 \quad \forall \varepsilon \in\left(0, \varepsilon^{*}\right),
$$

and

$$
\frac{(N-1) p(\varepsilon) f(\varepsilon)}{N}-p^{\prime}(\varepsilon)[1-F(\varepsilon)]=\frac{(N-1) C^{\prime}(\varepsilon / N) f(\varepsilon)}{N} .
$$

This differential equation can be solved by means of the integrating factor, $[1-F(\varepsilon)]^{\frac{N-1}{N}-1}$, to yield 


$$
p(\varepsilon)=\frac{A-\int^{\varepsilon}(N-1) C^{\prime}(u / N) f(u)[1-F(u)]^{\frac{N-1}{N}-1} d u}{N[1-F(\varepsilon)]^{\frac{N-1}{N}}} \forall \varepsilon \in\left[0, \varepsilon^{*}\right],
$$

where $A$ is an integration constant.

\section{Proof of Theorem 1}

It follows from (1) that for a given $S_{i}$, the expected profit from a marginal unit of firm $i$ is

$$
\varphi_{i}\left(S_{i}, p\right) d S_{i}=\left[p-C^{\prime}\left(S_{i}\right)\right]\left[1-F\left(S_{i}+S_{-i}(p)\right)\right] d S_{i},
$$

where $p=p_{i}\left(S_{i}\right)$ is the offer of the marginal unit. Because competitors follow the symmetric equilibrium candidate $\breve{S}_{i}$, (2) can be rewritten as

$$
\frac{\partial \varphi_{i}\left(S_{i}, p\right)}{\partial p}=1-F\left[\breve{S}_{-i}(p)+S_{i}\right]-\breve{S}_{-i}^{\prime}(p)\left(p-C^{\prime}\left(S_{i}\right)\right) f\left[\breve{S}_{-i}(p)+S_{i}\right]
$$

or

$$
\frac{\partial \varphi_{i}\left(S_{i}, p\right)}{\partial p}=f\left[\breve{S}_{-i}(p)+S_{i}\right]\{\underbrace{(\overbrace{\left(\frac{1-F\left[\breve{S}_{-i}(p)+S_{i}\right]}{f\left[\breve{S}_{-i}(p)+S_{i}\right]}\right)}^{\left.G(p)+S_{i}\right]}-\breve{S}_{-i}^{\prime}(p)\left(p-C^{\prime}\left(S_{i}\right)\right)\}}_{\eta\left(p, S_{i}\right)} .
$$

Let $p^{*}=\breve{p}_{i}\left(S_{i}\right)$. The first-order condition of the PABA in (4) ensures that $\left.\frac{\partial \varphi_{i}\left(S_{i}, p\right)}{\partial p}\right|_{p=p^{*}}=0$. The profit of a unit, $\varphi_{i}\left(S_{i}, p\right)$, is globally maximized at $p^{*}$ if $\varphi_{i}\left(S_{i}, p\right)$ is quasiconcave in $p$ or equivalently that it is single peaked. As $f>0$ and $\eta\left(p^{*}, S_{i}\right)=0$, this would be the case if $\eta\left(p, S_{i}\right)>0$ for $p \in\left[\breve{p}(0), p^{*}\right)^{9}$ and $\eta\left(p, S_{i}\right)<0$ for $p \in\left(p^{*}, \bar{p}\right]$. Now it will be analysed under what circumstances this occur. The following is known from (27):

$$
\eta\left(p, S_{i}\right)=G\left[\breve{S}_{-i}(p)+S_{i}\right]-\breve{S}_{-i}^{\prime}(p)\left(p-C^{\prime}\left(S_{i}\right)\right) .
$$

From the first-order condition in (5) it follows that

$$
\breve{S}_{-i}^{\prime}(p)=\frac{G[\breve{S}(p)]}{p-C^{\prime}\left(\breve{S}_{i}(p)\right)} .
$$

\footnotetext{
${ }^{9}$ It is never profitable to offer a unit below $\breve{p}(0)$, as the unit is always accepted at this price.
} 
Thus (28) can be written.

$$
\begin{gathered}
\eta\left(p, S_{i}\right)=\frac{\left(p-C^{\prime}\left(\breve{S}_{i}(p)\right)\right) G\left[\breve{S}_{-i}(p)+S_{i}\right]-G[\breve{S}(p)]\left(p-C^{\prime}\left(S_{i}\right)\right)}{p-C^{\prime}\left(\breve{S}_{i}(p)\right)}= \\
=\frac{\left[p-C^{\prime}\left(\breve{S}_{i}(p)\right)\right]\left[G\left[\breve{S}_{-i}(p)+S_{i}\right]-G[\breve{S}(p)]\right\}+G[\breve{S}(p)]\left(C^{\prime}\left(S_{i}\right)-C^{\prime}\left(\breve{S}_{i}(p)\right)\right)}{p-C^{\prime}\left(\breve{S}_{i}(p)\right)} .
\end{gathered}
$$

It follows from (4) that $p>C^{\prime}\left(\breve{S}_{i}\right)$ for increasing supply functions. Further, marginal costs are non-decreasing and $G(x)>0$, as the hazard rate is never negative. To prove claim ii) consider the case when $G(x)$ is monotonically increasing. If $p \in\left[\breve{p}(0), p^{*}\right)$ then $S_{i}>\breve{S}_{i}(p) \Rightarrow$ $C^{\prime}\left(S_{i}\right) \geq C^{\prime}\left(\breve{S}_{i}(p)\right)$ and $G\left(\breve{S}_{-i}(p)+S_{i}\right)>G(\breve{S}(p))$. Thus it follows from (29) that $\eta\left(p, S_{i}\right)>0$ $\forall p \in\left[\breve{p}(0), p^{*}\right)$. Analogously, it can be proven that $\eta\left(p, S_{i}\right)<0 \forall p \in\left(p^{*}, \bar{p}\right]$. The result is true for all $S_{i}$. Thus the profit of each unit of a firm is globally maximized, and there are no profitable unilateral deviations. Accordingly, the existence of a SFE is guaranteed for monotonically increasing $G(x)$, which proves claim ii.

There will certainly be deviations if the expected profit of some unit is locally minimised. Thus a necessary condition for a SFE is that all $S_{i}$ are at a local profit maximum. Accordingly, it is necessary that $\left.\frac{\partial \eta\left(p, S_{i}\right)}{\partial p}\right|_{p=p^{*}} \leq 0$ for all $S_{i}$. It follows from (29) that ${ }^{10}$

$$
\begin{aligned}
& \left.\frac{\partial \eta\left(p, S_{i}\right)}{\partial p}\right|_{p=p^{*}}=\frac{\left[p^{*}-C^{\prime}\left(\breve{S}_{i}\left(p^{*}\right)\right)\right]\left[\breve{S}_{-i}^{\prime}\left(p^{*}\right) G^{\prime}\left[\breve{S}\left(p^{*}\right)\right]-\breve{S}^{\prime}\left(p^{*}\right) G^{\prime}\left[\breve{S}\left(p^{*}\right)\right]\right\}}{p^{*}-C^{\prime}\left(\breve{S}_{i}\left(p^{*}\right)\right)}+ \\
& +\frac{G\left[\breve{S}\left(p^{*}\right)\right]\left(-\breve{S}_{i}^{\prime}\left(p^{*}\right) C^{\prime \prime}\left(\breve{S}_{i}\left(p^{*}\right)\right)\right)}{p^{*}-C^{\prime}\left(\breve{S}_{i}\left(p^{*}\right)\right)}= \\
& =-\breve{S}_{i}^{\prime}\left(p^{*}\right) \frac{\left[p^{*}-C^{\prime}\left(\breve{S}_{i}\left(p^{*}\right)\right)\right] G^{\prime}\left[\breve{S}\left(p^{*}\right)\right]+G\left[\breve{S}\left(p^{*}\right)\right] C^{\prime \prime}\left(\breve{S}_{i}\left(p^{*}\right)\right)}{p^{*}-C^{\prime}\left(\breve{S}_{i}\left(p^{*}\right)\right)}
\end{aligned}
$$

\footnotetext{
${ }^{10}$ Note that the differentiation involves the differentiation formulas for products and quotients, but most terms are zero because $S_{i}=\breve{S}_{i}\left(p^{*}\right)$. Thus there are only contributions when the derivative operates on either $G\left[\breve{S}_{-i}(p)+S_{i}\right]-G[\breve{S}(p)]$ or $C^{\prime}\left(S_{i}\right)-C^{\prime}\left(\breve{S}_{i}(p)\right)$.
} 
Thus if the expected profit should be maximised for each of the firm's units, then it is necessary that

$$
\left[p-C^{\prime}\left(\breve{S}_{i}(p)\right)\right] G^{\prime}[\breve{S}(p)]+G[\breve{S}(p)] C^{\prime \prime}\left(\breve{S}_{i}(p)\right) \geq 0 \forall p: S_{i}(p) \in(0, \bar{\varepsilon} / N),
$$

which proves claim i).

\section{Proof of Theorem 2}

From (5) it follows that the slope of a supply function in a PABA is given by:

$$
S_{i}^{\prime}=\frac{G\left[N S_{i}\right]}{(N-1)\left(p-C^{\prime}\left(S_{i}\right)\right)} .
$$

From (6) it follows that the slope of a supply function in a UPA is given by:

$$
S_{i}^{\prime}=\frac{S_{i}}{(N-1)\left(p-C^{\prime}\left(S_{i}\right)\right)} .
$$

Comparing this slope with the slope in PABA we can conclude that if $G(N x)>x$ then the marginal offer in PABA is more price-responsive $\left(S_{i}^{\prime}\right.$ is higher) for every pair $\left(p, S_{i}\right)$. As both supply functions fulfil the end-condition $p(\bar{\varepsilon})=\bar{p}$, this means that the marginal offer in PABA is higher than the marginal offer in UPA for $\varepsilon \in[0, \bar{\varepsilon})$ if $G(\varepsilon)>\varepsilon / N$. 